\title{
Evaluation of Thermoplastic Vulcanizates in Radomes
}

\author{
Alessandra de A. P. Gabino ${ }^{1, *}$, Tamara Indrusiak ${ }^{1,2}$, Bluma Guenther Soares ${ }^{1}$ \\ Gabino AAP (D) https://orcid.org/0000-0002-9775-7549 \\ How to cite \\ Indrusiak T (D) https://orcid.org/0000-0002-1025-8537 \\ Soares BG (iD https://orcid.org/0000-0002-1273-7574

\begin{abstract}
Gabino AAP; Indrusiak T; Soares BG (2019) Evaluation of thermoplastic vulcanizates in radomes. J Aerosp Technol Manag, 11, Special Edition: 33-36. https://doi. org/10.5028/jatm.etmq. 11
\end{abstract}

\begin{abstract}
The present paper evaluates a thermoplastic vulcanizate (TPV) of polypropylene (PP) and nitrile rubber (NBR), with and without carbon nanotube (CNT), with a potential application in structures that protect radar antennas, radomes. Morphological analysis, izod impact test, electromagnetic properties measurement and S-parameters were performed in order to verify its operational functioning. The presence of CNT affected the morphology of TPV, reducing the size of NBR particles. This enhanced impact strength results, besides the already known reinforcing effect of CNT on polymeric matrices. Electromagnetic parameters showed that both filled and unfilled TPV are low-loss materials. However, better impact result makes the filled TPV the most indicated material for radome application.
\end{abstract}

KEYWORDS: Thermoplastic vulcanizate; Radome; Impact; S-parameters.

\section{INTRODUCTION}

Antennas and radars are indispensable components in the fields of telecommunication, aerospace and military (Zhang et al. 2017). These gadgets are subjected to the most varied meteorological and mechanical conditions; therefore, a crucial apparatus is responsible for the structural protection of antennas called radomes (radar + dome). Radomes are physical barriers responsible for protecting antennas from rain, humidity, wind, fluids or aircraft fuel and solvents (Waqas et al. 2019). For such application, the constitutive material of a radome must be light, provide good structural rigidity and impact strength, as well as be transparent at the antenna's operation frequency and present low signal reflection on its surface, and this attribute is crucial for its proper performance (Choi et al. 2011). As a result, aircraft radomes are usually made of polymeric blends and/or composites, which provide excellent mechanical, thermal and electrical properties and corrosion resistance (Rodriguez et al. 2015).

Thermoplastic vulcanizates (TPVs) are polymeric blends in which elastomer particles are crosslinked and finely dispersed in a continuous thermoplastic matrix. These materials combine the elasticity of crosslinked rubber with the processing and recycling abilities of thermoplastics (Drobny 2014). Recently, due to pleas for environmental protection and conscious usage of resources, especially fossil, TPVs have received special attention (Ma et al. 2016), especially by substituting pure crosslinked rubber, which cannot be recycled.

The objective of this study is to evaluate the possible application as a radome material of a TPV made of polypropylene (PP) and nitrile rubber (NBR), filled and unfilled with carbon nanotube (CNT).

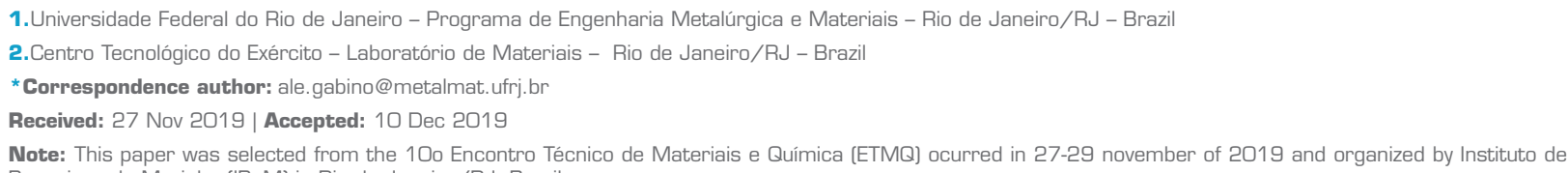




\section{MATERIALS AND METHODS}

Nitrile rubber (33\% acrylonitrile; Mooney viscosity $\left[\mathrm{ML} 1+4\right.$ at $\left.\left.100{ }^{\circ} \mathrm{C}\right]=50\right)$ was gently provided by Nitriflex Ind. e Com. S.A. Polypropylene CP 442XP (MFI $=6 \mathrm{~g} / 10 \mathrm{~min}$ at $230^{\circ} \mathrm{C}$ ) was supplied by Braskem S.A. Dicumyl peroxide (DCP) Retilox DPP 99\%, was provided by Retilox Soluções Tecnológicas. Rubber processing aid bis(2-ethylhexyl) phthalate (DOP) was donated by Petroflex Ind. e Com., and multiwalled carbon nanotube NC7000 was purchased from Nanocyl S.A.

Two samples, a TPV and a conductive composite based on the TPV and CNT, named CPC, were prepared in an internal mixer HAAKE Rheomix 600. A masterbatch (MB) of NBR and DOP (10 phr, i.e. parts per hundred resin) was premixed at $50^{\circ} \mathrm{C}$, $90 \mathrm{rpm}$ rotor speed for $10 \mathrm{~min}$. Both samples were prepared at $190^{\circ} \mathrm{C}$ and $90 \mathrm{rpm}$. First, MB was added. After 3 min, PP was added, according to the 50:50 NBR/PP proportion; after 3 more min, DCP was mixed (0.5 phr). Three min later, in case of CPC, CNT (0.2 phr) was added and mixed for $4 \mathrm{~min}$. The total mixing time was 9 min for TPV and 13 min for CPC.

Morphological analysis was conducted in a Scanning Electron Microscope TESCAN VEGA3, at $20 \mathrm{kV}$. The injection-molded specimen were cryogenically fractured and emerged in osmium tetroxide $\left(\mathrm{OsO}_{4}\right)$ for 90 min, for the preferentially staining of NBR phase. A backscattered-electron (BSE) detector was used. Impact test specimen were obtained in a HAAKE MiniJet injection molding system, at $190^{\circ} \mathrm{C}$ with pressure of 400 bar. Notched Izod impact test was conducted according to ASTM D256-10 in a Resil Impactor 5,5 J, from Ceast. Electromagnetic properties of real and imaginary permittivity ( $\varepsilon^{\prime}$ and $\varepsilon^{\prime}$ ), dielectric loss tangent $\left(\operatorname{tg} \delta_{\varepsilon}\right)$ and scattering parameters $\left(\mathrm{S}_{11}\right.$ e $\left.\mathrm{S}_{21}\right)$ were obtained at the X-band (8.2 to $\left.12.4 \mathrm{GHz}\right)$ in a vector network analyzer (VNA) PNA-L, from Agilent Technologies, coupled in a waveguide. Sample dimensions were $23 \times 10 \times 2 \mathrm{~mm}$.

\section{RESULTS AND DISCUSSION}

The morphology of TPV and CPC samples is presented in Fig. 1. Classic morphology of TPVs can be observed for both samples: rubber particles (lighter particles) dispersed in the thermoplastic matrix. As expected, CNT caused a reduction in the size of NBR domain, because the presence of a conductive filler tends to reduce interfacial tension between polymers in a blend (Dey et al. 2015).

(a)

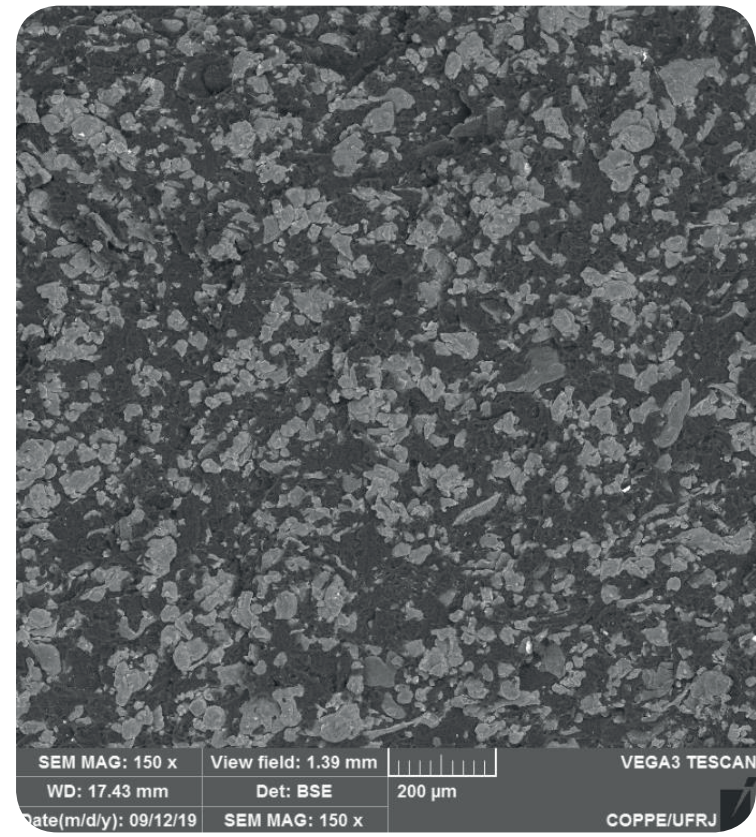

(b)

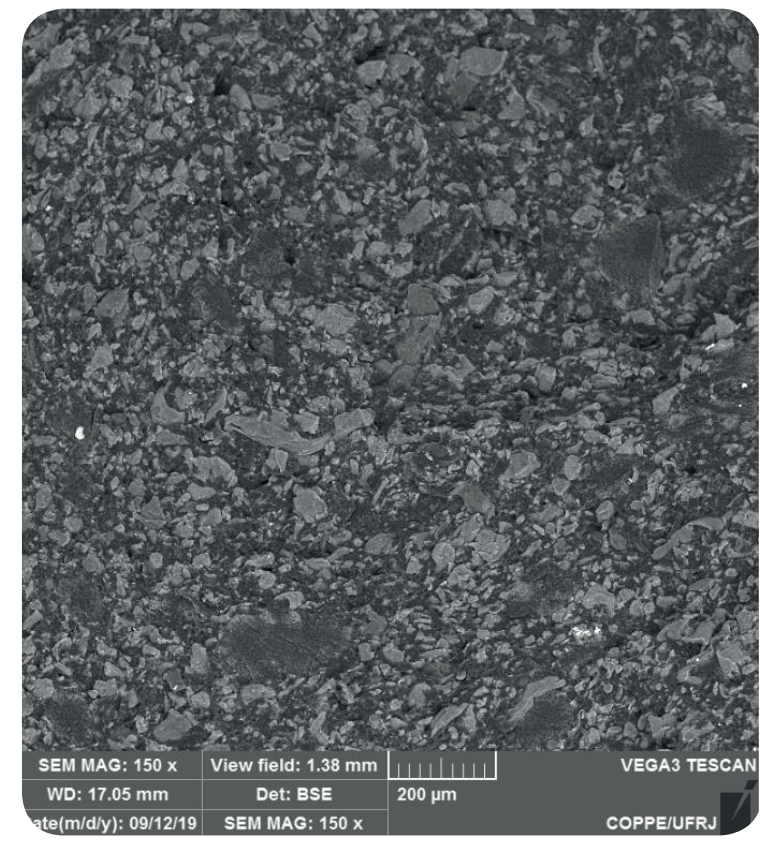

Figure 1. SEM images of (a) TPV; (b) CPC (Nominal zoom: 150x). 


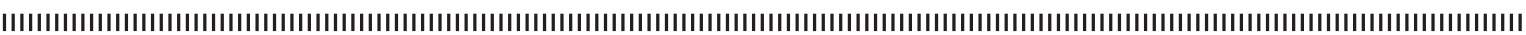

In the impact test, the $2.37 \mathrm{~J}$ hammer was not able to break the test specimen completely. Considering the hammer impact energy and the total length the fracture should go through $(10.16 \mathrm{~mm})$, estimated resilience of the samples were calculated: for TPV: $28.8 \mathrm{~J} / \mathrm{m}$, and for CPC: $42.2 \mathrm{~J} / \mathrm{m}$. Besides the reinforcing effect that CNT has on polymers, the enhanced impact strength of CPC can also be attributed to its finer morphology. The reduction of interfacial tension between NBR and PP, promoted by CNT, also contributes to better energy transference between the phases.

The results for the electromagnetic properties are presented in Fig. 2. Both TPV (Fig. 2a) and CPC (Fig. 2b) presented low values for $\varepsilon^{\prime}$ (2.4 and 2.7), $\varepsilon^{\prime \prime}(0.05$ and 0.15$)$ and $\operatorname{tg} \delta_{\varepsilon}(0.02$ and 0.05$)$. The slight increase observed in CPC is due to the presence of conductive filler. This indicates that both samples are low-loss materials, and this is one of the pre-requisites for being a radome (Kim et al. 2008). Low-loss materials provide good impedance matching between the air and its surface, mitigating reflection on the interface and minimizing signal loss (Wahab 2009).

(a)

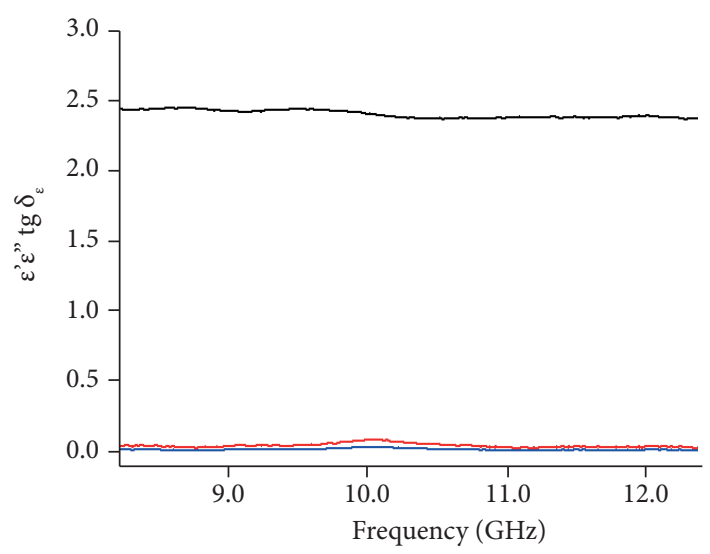

(b)

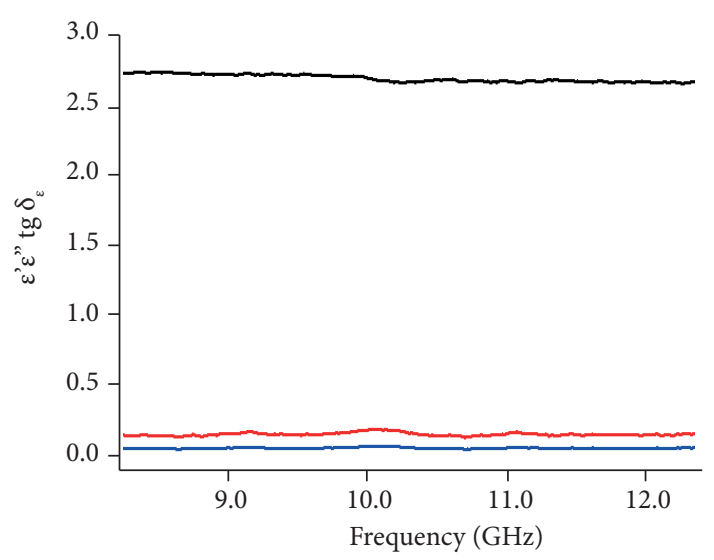

Figure 2. Dielectric properties of: (a) TPV; (b) CPC.

Scattering parameters, or S-parameters, presented in Fig. 3, reveal that both materials have low reflection property. Parameter $\mathrm{S}_{21}$ corresponds to the transmitted signal and $\mathrm{S}_{11}$ to the reflected signal. Low values of permittivity and dielectric loss tangent and high values of $\mathrm{S}_{11}(-9$ and $-8 \mathrm{~dB}$, for TPV and CPC respectively) denote low reflection for both samples. In addition, high values of $\mathrm{S}_{21}(-0.8$ and $-1 \mathrm{~dB}$, for TPV and CPC respectively) reveal that 90 and $80 \%$ of the incident signal are transmitted in most part of the analyzed frequency range, which is another pre-requisite for radomes (Kim et al. 2008). Such characteristic is related to the transparency at the operation range.

(a)

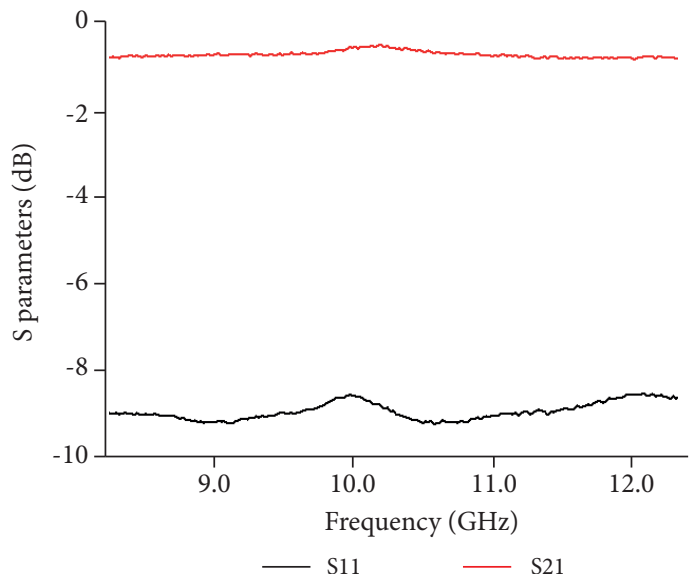

(b)

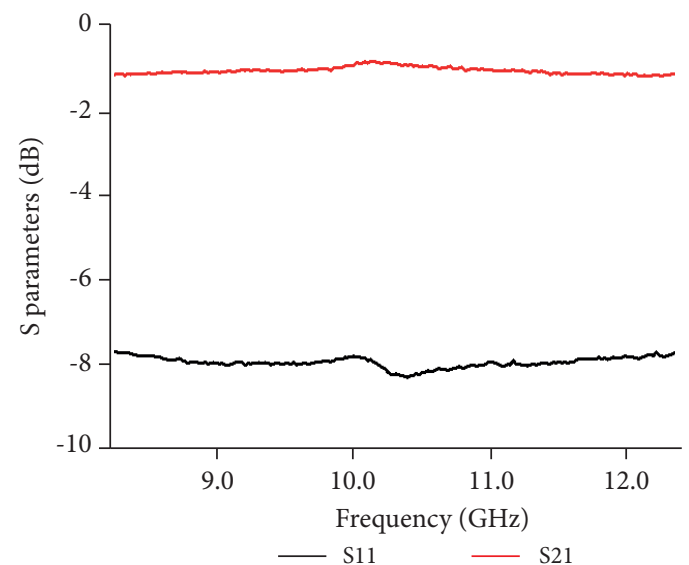

Figure 3. Scattering parameters of: (a) TPV; (b) CPC. 


\section{CONCLUSION}

Both samples of TPV, filled and unfilled with CNT, present low dielectric properties and scattering parameters, which fit in the requisites of impedance matching and radar operation frequency transparency. Because CPC presented higher impact strength, due to the presence of $\mathrm{CNT}$, it is the most suitable for radome application.

\section{ACKNOWLEDGMENTS}

The authors are grateful to Nitriflex Ind. e Com. S.A. for the material donated.

\section{FUNDING}

Coordenação de Aperfeiçoamento de Pessoal de Nível Superior [http://doi.org/10.13039/501100002322]

Conselho Nacional de Desenvolvimento Científico e Tecnológico [http://doi.org/10.13039/501100003593]

Fundação de Amparo à Pesquisa do Estado do Rio de Janeiro [http://doi.org/10.13039/501100004586]

\section{AUTHORS' CONTRIBUTION}

Conceptualization, Gabino A and Indrusiak T; Methodology, Gabino A and Indrusiak T; Research, Gabino A and Indrusiak T; Writing - First version, Gabino A and Indrusiak T; Writing - Review \& Editing, Gabino A; Acquisition of Funding, Soares B; Resources, Soares B; Supervision, Soares B.

\section{REFERENCES}

Choi I, Kim JG, Lee DG, Seo IS (2011) Aramid/epoxy composites sandwich structures for low-observable radomes. AIP Conf Proc 71(14):1632-1638. https://doi.org/10.1016/j.compscitech.2011.07.008

Dey P, Naskar K, Dash B, Nair S, Unnikrishnan G, Nando G (2015) Selective dispersion of carbon fillers into dynamically vulcanized rubber/ plastic blends: A thermodynamic approach to evaluate polymer reinforcement and conductivity enhancement. RSC Adv 5(40):1-64. https://doi.org/10.1039/C4RA16941G

Drobny JG (2014) Handbook of Thermoplastic Elastomers. 2nd ed. San Diego: Elsevier.

Kim PC, Lee DG, Seo IS, Kim GH (2008) Low-observable radomes composed of composite sandwich constructions and frequency selective surfaces. Compos Sci Technol 68(9):2163-2170. https://doi.org/10.1016/j.compscitech.2008.03.016

Ma L, Bao R, Liu Z, Yang W, Yang M (2016) Effect of cross-linking degree of EPDM phase on the electrical properties and formation of dual networks of thermoplastic vulcanizate composites based on isotactic polypropylene (iPP)/ethylene-propylene-diene rubber (EPDM) blends. RSC Adv 6(78):74567-74574. https://doi.org/10.1039/C6RA14731C

Rodriguez LA, García C, Grace LR (2015) The effect of in-service aerospace contaminants on X-band dielectric properties of a bismaleimide/ quartz composite. AIP Conference Proceedings, 1664(1):060005.1- 060005.5. https://doi.org/10.1063/1.4918423

Waqas HM, Shi D, Imran M, Khan SZ, Tong L, Ahad F, Zaidi AA, lqbal J, Ahmed W (2019) Conceptual design of composite sandwich structure submarine radome. Materials 12(12):1966-1918. https://doi.org/10.3390/ma12121966

Wahab M (2009) Radar radome and its design considerations. International Conference Instrumentation, Communication, Information Technology and Biomedical Engineering; Bandung, Indonesia. https://doi.org/10.1109/ICICI-BME.2009.5417229

Zhang F-S, Xu J-Z, Xu G-D, Zu L (2017) The buckling behavior of radome with different braided angles based on CFRP. Compos Struct 176:597-607. https://doi.org/10.1016/j.compstruct.2017.05.067 